\title{
A saúde na metrópole
}

José R. CARVALHEIRO

\section{0 recorte espacial e temporal}

$\mathrm{H}$

A UM VASTO material bibliográfico disponível para os interessados na recuperação da memória da Saúde Pública no Brasil e mesmo em São Pau-

lo, por isso, este artigo não irá se deter em comentários a este respeito. N o processo social de construção do sistema de saúde no Brasil, para se compreender o presente é necessário reconhecer num passado recente a esquizofrenia do arranjo que situou 0 atendimento público individual numa determinada rede, e as ações coletivas em outra. 0 atendimento individual (assistência médica), a princípio, era de responsabilidade dos Institutos de Previdência especializados segundo categoria profissional. C om a sua unificação, passaram a compor o I nstituto N acional de Assistência M édica da Previdência Social (I namps), do M inistério do Trabalho e da Previdência Social (MTPS). As ações coletivas, ou de Saúde Pública propriamente dita, eram de responsabilidade do M inistério da Saúde. Tinham como princípio básico a universalidade e geralmente gozavam daquilo que os economistas denominam "ações com fortes externalidades positivas", ou que têm efeitos para além do âmbito restrito em que se aplicaram. As ações individuais, ao contrário, eram destinadas apenas a uma parcela da população brasileira: os trabalhadores com carteira assinada e seus dependentes. Sobravam os muito ricos e os muito pobres, que dispunham de mecanismos bastante diferentes na busca da atenção. Filantropias e hospitais-escola para os pobres, chamados "indigentes" ; medicina privada para os abonados. A discussão a partir do final dos anos de 1970 redundou, já no início da década de 1980, em diversos ensaios de unificação, em particular, colocando à prova o princípio da universalidade também na assistência médica às pessoas. São exemplos claros as Ações Integradas de Saúde (AIS) e o Sistema U nificado e D escentralizado de Saúde (Suds), espalhados por todo o país e que tiveram no Estado de São Paulo, inclusive na sua capital e R egião M etropolitana, iniciativas claras.

M omentos marcantes foram a VIII Conferência N acional de Saúde, em 1986, e a sua seqüência, na Comissão N acional da R eforma Sanitária (CN RS), que levou ao debate da Assembléia $\mathrm{N}$ acional Constituinte as posições defendidas pelo "M ovimento Sanitário" e pactuadas, no processo, junto ao "Centrão". O resultado disso foi o capítulo referente à saúde na Constituição de 1988, o qual definiu para o Brasil um Sistema Ú nico de Saúde (SU S), cujas idéias prevalecentes eram as de "Saúde para Todos", alardeadas internacionalmente pela O rganização M undial da Saúde (OM S) e perfeitamente congruentes com o conceito de "seguridade social" surgido nas discussões do processo constituinte. As leis fun- 
damentais do SU S (8.080 e 8.142) são de 1990, portanto, éimportante reconhecer, ao se analisar o atual momento da saúde no país, no E stado, no M unicípio de São Paulo ou em Região M etropolitana, que se trata de um processo recente, embora tenha raízes profundas no pensamento crítico da saúde, muito mais antigo. É necessário reconhecer, ainda, as contradições de um processo político que os sanitaristas continuam considerando o mais importante movimento social contemporâneo no Brasil: nem mesmo os trabalhadores rurais, organizados no M ST, mobilizam uma tão expressiva massa de militantes, espalhados por todo 0 território nacional, com organização formal em cada um dos quase seis mil municípios. É bem verdade que o processo de implantação do SU S pode ser considerado exemplar para qualquer outro que busque integrar os três níveis de governo, incluindo as relações com o L egislativo e o J udiciário, além do M inistério Público e da necessária participação da sociedade. É de hoje a proposta de "cópia" do modelo no terreno da Segurança Pública, com progressiva adesão dos E stados ao Susp, pois nem todos ainda o fizeram. Passados quase treze anos, na área da saúde o quadro é bem diferente: to dos os Estados estão no SU S. N o caso do Estado de São Paulo, apenas dois dos seus 645 municípios não fazem parte do SU S, de modo que o M unicípio de São Paulo e, em decorrência, o Estado, acabam de ser habilitados na categoria de "gestão plena do sistema", conferindo maior autonomia na definição dos rumos do SU S com feições próprias.

Por todo esse passado de gloriosos momentos de explícito ativismo coletivo, os sanitaristas insistem em afirmar que o SU S não deve ser considerado propriedade de partido político algum nem de nenhum particular governo, em qualquer nível. N esse sentido, sua construção é a de uma política de Estado, pertence ao país e a seu povo. M al comparando, guarda alguma semelhança com a seleção brasileira de futebol, ou "a pátria em chuteiras", na feliz expressão de N elson Rodrigues. Resta saber o que pensa a população a respeito ou, ainda, "o que é 0 SU S para os diversos atores sociais".

Talvez existam tentativas de estabelecer um procedimento padrão para avaliar a implantação de uma política pública. Terreno constante de disputa entre correntes de pensamento, são questionados os próprios instrumentos "objetivos" de julgamento: tanto do processo como, especialmente, dos resultados.

As avaliações de desempenho do SU S por meio de declarações de satisfação do usuário atendem mais aos interesses de quem as divulga. O SU S do M inistro J osé Serra, ainda hoje encontrado no site do M inistério da Saúde (M S, 2003), foi avaliado por meio do envio de quase um milhão de cartas pessoais aos egressos de hospitais do SU S. As repostas de "mais de 110 mil pessoas" dão um índice de satisfação de $85 \%$ que o consideram "excelente ou bom". O Conselho Regional de M edicina de São Paulo (Cremesp), analisando um levantamento em 1.011 unidades hospitalares de média e alta complexidade no Estado, deu margem a que a reportagem da Folha de S.Paulo (2003) afirmasse em manchete que "os hospitais de São Paulo agonizam". Em extensa reportagem, o jornal O Estado de 
S.Paulo (2003) afirma que o problema do SU S "é menos de qualidade do que de acesso aos serviços", o que não deixa de ser um elogio. O SU S dos sanitaristas militantes, obviamente, é muito diferente daquele apresentado de maneira impiedosa e escrachada pelo humorista Tom Cavalcanti num programa de TV de grande audiência. 0 epistemólogo argentino Juan Samaja tem repetidas vezes afirmado que, no processo de explicação do mundo, transdisciplinaridade só não basta. É indispensável aproveitar contribuições advindas de áreas não reconhecidas como disciplinas científicas. Inclui aí a linguagem artística, religiosa, os chistes etc. É melhor, segundo esse autor, pensar numa "trans-sapiência" o que vem bem a calhar: o SU S, possivelmente, é tudo isso e muito mais!

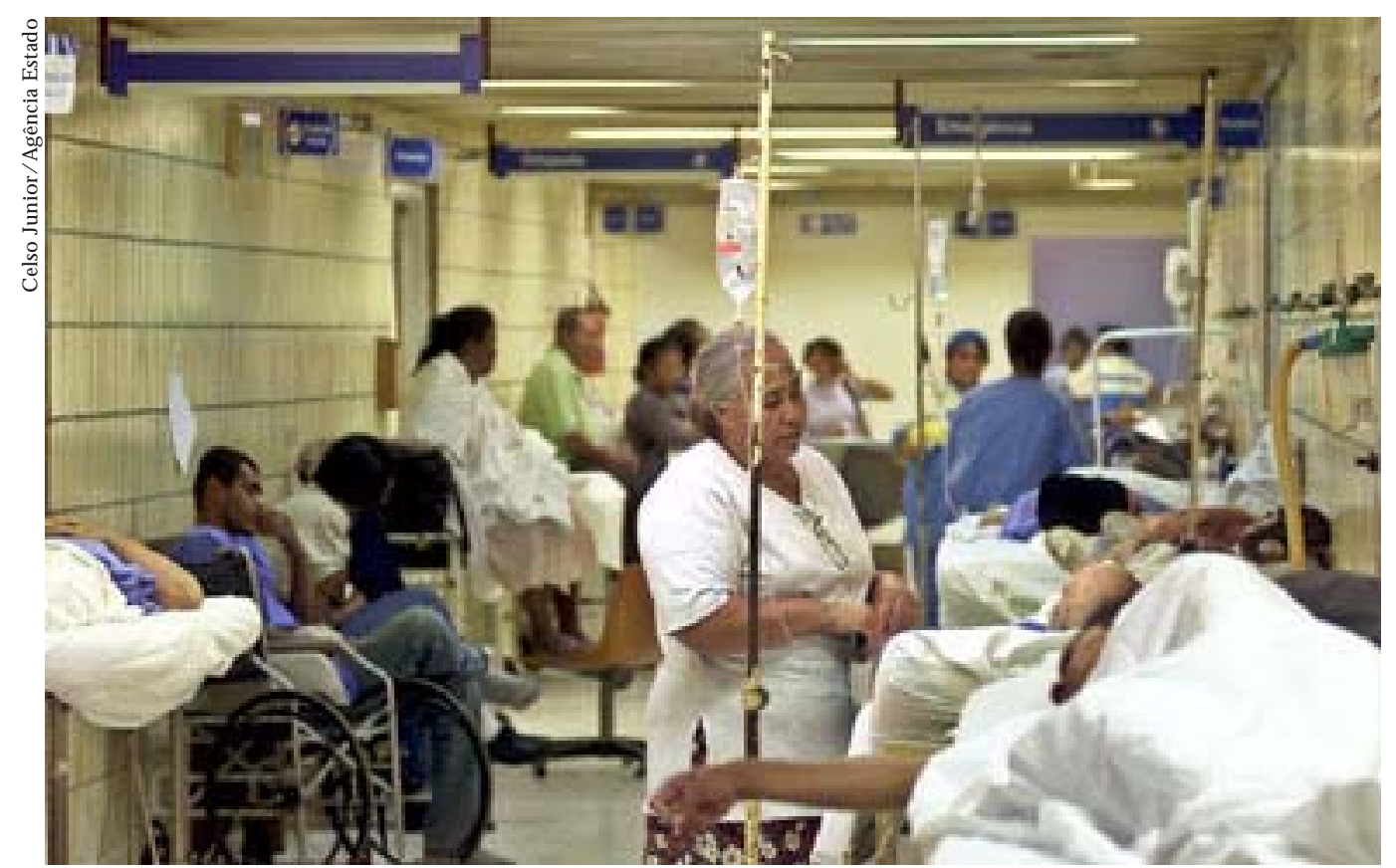

Corredor do H ospital M unicipal D r. A rthur R ibeiro Saboya, no J abaquara, zona sul de São Paulo.

\section{As propostas "objetivas" de avaliação pelos indicadores de saúde}

A situação de saúde pode ser vista por diversos ângulos. D esde há muito os sanitaristas definiram "indicadores" capazes de traduzir a qualidade coletiva da saúde dos povos. Em nosso caso, podem ser acessados no site do M inistério da Saúde (M S, 2003), no da O pas (2003) ou no da Bireme (2003). Entre outros conjuntos de dados, um muito valorizado é o da Rede Interagencial de Informações para a Saúde (Ripsa, 2002) resultante de um consenso amplo de especialistas. Existem outros métodos, entre elesum sintético e muito difundido na atualidade, o da "C arga da D oença", ou "Fardo da D oença" ("Burden of Disease" ou BoD )

A situação, em nosso caso, pode ser vista pela A genda do SU S (M S, 2003). Esta, um esforço do M inistério da Saúde, definiu os problemas que merecem 
entrar para o elenco pos problemas prioritários para o SU S. D efiniram-se al guns indicadores para acompanhar a evolução em todo o território nacional. Cada Estado, adaptou a Agenda a seu contexto e há previsão de que os M unicípios façam o mesmo. A idéia, de certa forma, copia o "H ealthy People 2010" (U SA, 2003), muito mais complexo e elaborado. N ão podemos deixar de mencionar, nesse sentido, uma recente e extremamente complexa avaliação do desempenho dos serviços nos EU A (M cGlynn et al., 2003), feita em entrevista telefônica com autorização do acesso dos investigadores aos prontuários médicos. Entrevistando mais de treze mil adultos em doze áreas metropolitanas, concluíram que apenas $55 \%$ dos cuidados recomendados foram atendidos. $\mathrm{N}$ ada que se compare ao que temos feito no Brasil mas, ainda assim, é possível questionar alguns dos índices de desempenho empregados.

\section{O D ossiê Saúde Pública (1999) e os dez anos de desafio do SU S (2002) como fontes de inspiração}

Ao preparar este trabalho, adotamos duas fontes principais: a publicação do D ossiê Saúde Pública (IEA, 1999); e a obra de N egri e Viana, 2002, publicada pelo M inistério da Saúde em parceria com a Sociedade Brasileira de Vigilância de M edicamentos (Sobravime) e o Centro de Estudos Augusto Leopoldo Ayrosa Galvão (C ealag). Em ambas, o leque de colaboradores foi muito amplo. 0 conteúdo cobriu uma sucinta visão geral da situação internacional como referência, mas deteve-se fundamentalmente na análise dos principais pontos do processo recente de implementação do SU S no Brasil: assistência, financiamento, descentralização. A relação público/ privado mereceu também destaque em ambos os trabalhos.

O capítulo de I ntrodução da segunda das obras mencionadas, de autoria do então M inistro de Estado da Saúde, Barjas N egri, sintetiza numa visão "oficial" o discurso do que foram avançoselimitesnosanos de 1990. Considera quatro eixos de análise e o simples enunciado do contraste que faz entre o início e o fim da década (colocado abaixo entre parênteses e separado por barra) nos dá idéia do que considerou avanços:

- o marco institucional (a construção do SU S/ a execução da descentralização);

- o financiamento (indefinição e crise/ a procura da solidez);

- a gerência do SU S (baixo controle e pouca capacidade de intervenção/ meIhorias na gerência e na capacidade de regulação);

- a redução das desigualdades (pouca capacidade de ação/ alocação de recursos diferida).

N este quadro relativamente favorável (ou autocomplacente?) da situação do processo de implementação do SU S no país, o que ocorre na maior metrópole do país adquire especial significado. Em particular pelas dificuldades inerentes a um processo, já por si contraditório, em sua versão numa localidade de extrema complexidade econômica, social e política. 


\section{Formular e implementar políticas: as comunidades epistêmicas}

No primeiro dos trabalhos mencionados no item anterior, no capítulo introdutório (Carvalheiro, 1999), destacou-se o conceito de "comunidade epistêmica" no sentido que Ihe é conferido por H aas (1992) e apropriado no terreno da saúde internacional por M elo e Costa (1994). U m trabalho relativamente recente (Sutton, 1999) avança no sentido de associar à comunidade epistêmica uma "malha política" (policynetwork), emprestando ao conjunto uma dinâmica que incorpora a idéia de contradições internas e é mais plausível com o mundo real. Em particular, identifica os "grupos de interesse" (interest groups) como elementos essenciais na análise dos rumos do processo de implantação de uma política. M ais que isso, avança no sentido da discrepância entre o esforço dos que formulam as políticas (policy makers) e a realidade concreta enfrentada por aqueles que as implementam na prática. $\mathrm{O}$ u os responsáveis pela "burocracia ao rés do chão" (street level bu reaucracy). E ssas instâncias são representadas pelas escolas, as delegacias de polícia, os juizados de pequenas causas e, em nosso caso, centros de saúde, hospitais, laboratórios etc. $\mathrm{N}$ ada mais exemplar do que a realidade do SU S das ruas, como contraponto cruel ao SU S dos gabinetes.

$\mathrm{N}$ a escolha dos autores dos trabal hos apresentados neste dossiê pesaram duas idéias principais. Em primeiro lugar, a convicção de que o SU S está em pleno processo de implementação e, portanto, trata-se de analisar um peculiar desenlace provisório no município e na Região Metropolitana mais complexos do país. A lém disso, a idéia de Cecília D onnangelo comentando a produção científica na área de Saúde Coletiva: "somos um conjunto maior de atores do que de autores", referia-se, no início da década de 1980, antes mesmo da VIII Conferência $\mathrm{N}$ acional de Saúde, ao conjunto de intelectuais que construíram o pensamento crítico brasileiro em saúde. 0 s dois atores/ autores dos trabalhos apresentados são sem dúvida os protagonistas do processo em curso, no período escolhido para análise: os Secretários da Saúde do E stado de São Paulo, J osé da Silva G uedes, e do M unicípio de São Paulo, Eduardo Jorge. N um sentido muito preciso, ambos pertencem à mesma comunidade epistêmica que congrega acadêmicos, ativistas políticos, gestores públicos, corporações profissionais, associações de portadores de patologias e/ ou de deficiências etc. Embora se autodefinam em seus textos como pertencendo ao campo social democrata num caso e ao campo socialista, no outro, ambos participaram com o melhor de seus esforços na construção de um projeto de organização das ações de saúde num país capital ista na periferia do mercado globalizado. País muito distante de uma organização socialista do modo de produção e que nunca, de fato, pode ter sido considerado sequer próximo de um Estado capitalista "de bem estar social" (welfare state). E é nessa imensa contradição que os sanitaristas têm que se mover, o que lhes confere uma certa aura de santidade, ou melhor, de opção simultânea pelos pobres e pela pobreza. 0 que é um profundo equívoco: para ter um verdadeiro sucesso, o SU S precisa ser para todo o povo brasileiro e não apenas para o estrato dos despossuídos, 
ou have nots que é como os textos das agências econômicas multilaterais tratam os pobres, por oposição aos haves. No exercício do cargo de gestor do SU S, em seus respectivos níveis, os dois autores convidados foram verdadeiros "craques", bem distantes da figura anedótica que o já mencionado $\mathrm{N}$ el son Rodrigues usava para estigmatizar os atores medíocres do cinema nacional: "são incapazes de cobrar um escanteio".

\section{Bibliografia}

BIREM E. site: www.bireme.br, 2003.

CARVALHEIRO, J. R . (1999) "O s desafios para a saúde". Estudos A vançados, n. 35, 1994, pp. 7-20.

FSP. "H ospitais de SP agonizam, revela pesquisa”. Folha de S. Paulo, 22 jun. 2003. Caderno Cotidiano, p. C1, 2003.

H AAS, P. M. "Knowledge, Power, and Iternational Policy Coordination: Epistemic Communities and International Policy Coordination". International Organization, vol. 46, n. 1, 1992, pp. 1-35.

IEA. D ossiê Saúde Pública. Estudos A vançados, n. 35, 1999, pp. 7-155.

M CGLYN N, E. A. ; ASCH , S. M .; ADAM S, J .; KEESEY, J.; HICKS, J.; DECRISTOFARO, A. e KERR, E. A. "The Q uality of $\mathrm{H}$ ealth Care Delivered to Adults in the $\mathrm{U}$ nited States". N ew England J. M ed. vol. 348, 26 jun. 2003, pp. 2635-2645.

MELO, M. A .B. C. e COSTA, N.R. “D esenvolvimento sustentável, ajuste estrutural e política social: as estratégias da O M S/ O PS e do Banco M undial para a atenção à saúde". Planejamento e Políticas Públicas, I pea, n. 1, 1994, pp. 49-108.

M S site: www.saude.gov.br, 2003.

NEGRI, B. e Viana, A. L. A. (org.) O Si stema Ú nico deSaúdeem dez anosdedesafio. São Paulo, Sobravime/ Cealag, 2002.

OESP. "SU S: maior problema é de acesso aos serviços". O Estado de S. Paulo, 29 jun. 2003, Caderno A, pp. 14-16.

OPAS site: www.opas.org.br, 2003.

RI PSA. I ndi cadores bás cospara a saúdeno Brasil: conceitose aplicações Brasília, O rganização Pan- Americana da Saúde, 2002, 299 p.

SU TTO N, R. "The Policy Process: An O verview". Working Paper 118. London, O verseas D evelopment I nstitute Portland H ouse, 1999, 35 p.

U SA. site: www.healthypeople.gov, 2003.

J osé R.C ar valhei ro é médico formado pela Faculdade de M edicina da U SP em 1961, e professor titular de M edicina Social da Faculdade de M edicina de Ribeirão Preto.

Texto recebido e aceito para publicação em 4 de julho de 2003. 
